\title{
ms:aico
}

\section{A criação da}

Escola de

\section{Paraquedistas (1945)}

Claudius Gomes de Aragão Viana ${ }^{1}$

\section{The Brazilian Army \\ Paratroopers \\ Training School (1945)}




\section{Resumo:}

O artigo narra a criação e o desenvolvimento da Brigada de Infantaria Paraquedista do Exército Brasileiro. Descrevem-se os antecedentes, as ações e alguns dos principais personagens presentes na fundação do corpo de paraquedistas militares no Brasil, consolidada no período imediatamente subsequente ao final da Segunda Guerra Mundial.

Palavras-chave: História Militar, Exército Brasileiro, Paraquedistas militares.

\section{Abstract:}

The paper tells the creation and development of Parachute Infantry Brigade, a Brazilian Army troops. It describes the history, actions and some of the main characters present at the fundacion of the paratroopers in Brazil, consolidated in the period immediately following the end of World War II.

Keywords: Military History, Brasilian Army, Paratroopers. 


\section{Apresentação}

Neste trabalho apresentaremos os primeiros resultados de uma pesquisa em curso, que tem como tema a história da criação e do desenvolvimento da Brigada de Infantaria Paraquedista do Exército Brasileiro. Serão descritos os antecedentes históricos do corpo de paraquedistas militares no Brasil e as ações de alguns dos principais personagens que articularam sua fundação, consolidada no período imediatamente subsequente ao final da Segunda Guerra Mundial.

Uma sucessão de episódios evidencia a participação da tropa paraquedista nas principais intervenções militares na sociedade brasileira no período após a Segunda Guerra Mundial, seja em ações de repressão durante o regime militar, seja em ações humanitárias ou de segurança pública em épocas mais recentes. Com efeito, esse grupamento de militares foi empregado pelo governo brasileiro na contenção da revolta dos sargentos em Brasília e dos oficiais da Força Aérea Brasileira em Jacareacanga e Aragarças, na região amazônica, na década de 1960; nas ações militares na região do Araguaia no início da década de 1970; na composição das tropas das Forças de Paz da Organização das Nações Unidas no Panamá, em 1960 e em Moçambique, Angola, Timor Leste e Haiti, a partir dos anos 1990; e nas operações de pacificação dos complexos da Penha e do Alemão em 2010 e da Maré em 2014, no Rio de Janeiro, junto às forças de segurança pública do estado.

Trata-se, portanto, de uma instituição cujos integrantes estiveram inseridos em fatos marcantes nos campos político e social, como pode ser reconhecido nas suas ações ao longo do tempo. Apesar disso, a tropa paraquedista frequentou durante sete décadas os noticiários nacionais sem despertar maior interesse de cientistas sociais ou historiadores. Essa lacuna no conhecimento se deve à escassez, ou ainda ao pequeno leque de abordagens nos estudos sobre os militares e suas organizações, em geral, e sobre a Brigada de Infantaria Paraquedista, em particular. Existe uma série de questões não abordadas ou insuficientemente esclarecidas pela literatura atualmente disponível, que carece de subsídios e referências para uma discussão mais aprofundada. Os elementos apresentados no presente artigo visam fornecer parte desse subsídio, uma vez que nos levantamentos realizados até agora foram encontradas fontes de consulta relativamente desorganizadas e, a nível acadêmico, uma total ausência de estudos sobre o assunto. Grande parte das informações atualmente disponíveis são fontes primárias produzidas pela própria instituição, que mantém um espaço denominado "Museu Aeroterrestre", onde expõe a militaria reunida ao longo de seus setenta anos de existência e uma pequena sala onde funciona a "Seção Histórica", com um limitado acervo de documentos ligados à sua memória. Nenhuma referência foi encontrada nos periódicos especializados, nos repositórios de publicações das principais universidades ou no banco de teses da CAPES, no qual existe um único estudo a nível stricto sensu (Bruno, 2010), tratando de entrevistas com oficiais em serviço na brigada. 


\section{Contexto e antecedentes históricos}

O ano de 1945, que nos traz como principal lembrança o final da Segunda Guerra Mundial, também foi marcado no Brasil pelo processo de redemocratização que pôs fim ao Estado Novo e à ditadura de Getúlio Vargas. Temos aqui dois eventos notáveis em suas implicações para o desenvolvimento do Exército Brasileiro na segunda metade do século XX. Em primeiro, a relevância dos militares na articulação e no apoio armado à Revolução de 1930, continuada na nomeação de oficiais das Forças Armadas para a ocupação de importantes e variados cargos na administração federal e dos estados durante os quinze anos do governo de Vargas. Observa-se que nesses anos o Exército foi favorecido por uma série de grandes investimentos, que possibilitaram a modernização e o desenvolvimento da infraestrutura de suas unidades. Para citar apenas o caso da cidade do Rio de Janeiro, datam desse período a construção e a revitalização de fortalezas, quartéis, depósitos, fábricas, moradias, áreas de instrução e até mesmo linhas ferroviárias mantidas sob administração militar, instaladas tanto em bairros tipicamente caracterizados como sede de aquartelamentos, como a Vila Militar de Deodoro e o Campo dos Afonsos, quanto em outros locais como São Cristóvão, Praia Vermelha, Realengo, Triagem, Copacabana e Grajaú. Na área central da cidade, o maior exemplo dessa afirmativa foi a remodelação da monumental sede do Comando Militar do Leste, então ocupada pelo Ministério da Guerra ${ }^{1}$. De fato, em um período de dez anos após a revolução já encontraremos descrições bastante diversas daquelas que se referiam ao Exército de 1918, período que coincide com o final da Primeira Grande Guerra: "uma instituição atrasada", que utilizava um armamento "diversificado, dificultando a instrução e a manutenção", ocupava "instalações e quartéis precários" e era contemplada com "baixos orçamentos destinados pelo Congresso Nacional" (Rodrigues, 2007, p. 1).

Também podemos observar, além da evolução da infraestrutura dos aquartelamentos, a preocupação da instituição com o aperfeiçoamento dos seus recursos humanos. Em contraste, por exemplo, com as cinco escolas de formação que funcionavam nas duas primeiras décadas do século XX, em 1939, já existiam 25 estabelecimentos de ensino militar no País (Viana, 2010), em grande parte instalados em edificações novas, com obras em andamento ou recentemente concluídas, impulsionadas pelos recursos financeiros concedidos pelo governo.

\footnotetext{
${ }^{1}$ Essa é uma exposição reduzida dos elementos que observei e descrevi em História, memória e patrimônio da Escola Militar do Realengo (2010), dissertação apresentada no Mestrado em Bens Culturais e Projetos Sociais da Fundação Getúlio Vargas. Por ocasião daquela pesquisa, observamos, além dos memoriais descritivos, o próprio padrão arquitetônico de tais construções, cujo estilo revela as datas das respectivas construções. Sua expansão é notável no período considerado. O maior conjunto de depósitos e fábricas (do Ministério da Guerra) estavam localizados nos bairros de Realengo, Triagem e Jacaré. Quanto às linhas férreas, apontamos o funcionamento de ao menos duas: uma que ligava o ramal de Santa Cruz, na altura da estação de Realengo, à Fábrica de Cartuchos do Realengo; e o desvio do ramal de Deodoro a partir da estação de Bento Ribeiro, que atravessava o bairro de Marechal Hermes até o interior da Base Aérea dos Afonsos (então Escola Militar de Aviação), ambos já erradicados.
} 
Em segundo lugar, a experiência da participação do Brasil no conflito mundial reforçou a percepção da necessidade de modernização das suas forças militares, como revelam as considerações finais do Relatório Anual do Estado-Maior do Exército de 1945, que também enfatizava a conveniência da adoção da organização e da doutrina militares norteamericanas (Rodrigues, 2008). Tratava-se da consolidação de um processo em curso: mesmo nos anos anteriores à guerra já era observado o trânsito progressivo dos materiais e doutrinas de emprego militar, dos padrões alemães e franceses dominantes nas décadas anteriores, para os novos conceitos e materiais bélicos oriundos dos Estados Unidos da América, adotados pela Força Expedicionária Brasileira durante a guerra.

Esse resumido quadro revela uma conjuntura nacional de busca pela estabilidade e pela democracia no campo político e de impulsos modernizadores na área militar. Nele, como veremos adiante, foi assinado o decreto de criação da Escola de Paraquedistas, formada inicialmente por um pequeno grupo de quarenta e sete militares, que constituíram uma das primeiras instituições destinadas à formação de tropas paraquedistas na América Latina e, até hoje, a única no Brasil.

Encontramos as primeiras referências à criação das tropas paraquedistas - ou aeroterrestres, no jargão castrense - não em relatórios militares, mas em jornais e revistas datados de meados da década de 1930, dando conta que os exércitos russo e alemão haviam inaugurado centros de treinamento para habilitar grandes contingentes de soldados a saltarem de aeronaves em voo, conferindo rapidez, mobilidade e agressividade nas batalhas. Em 1940, foi a vez do Departamento de Defesa norte-americano anunciar a criação de um curso de paraquedismo para seu próprio exército, em Fort Benning, na Georgia. A história posteriormente registrada nas páginas institucionais do Exército Brasileiro e da própria Brigada Paraquedista situa nesse contexto as origens do paraquedismo militar brasileiro: segundo tais informações, o capitão Roberto de Pessôa foi enviado em 1944 para os Estados Unidos a fim de realizar o airborne course, e no retorno ao Brasil encarregou-se de selecionar e liderar outros quarenta e seis voluntários para também realizarem o curso de paraquedismo em Fort Benning. Esses militares utilizaram então o conhecimento das técnicas aprendidas no exército norte-americano para dar origem à Escola de Paraquedistas, versão nacional da United States Army Airborne School.

Essa, como dissemos, é uma narrativa oficial, divulgada e registrada institucionalmente. Embora a tenhamos apresentado de forma resumida, suas variantes mais extensas não apresentam muitos elementos adicionais (uma versão dessa história foi publicada, recentemente, em um número especial de Tecnologia \& Defesa, revista dos setores de Defesa, Aeroespacial e Segurança Pública, por ocasião da passagem dos setenta anos de assinatura do decreto de criação da Escola de Paraquedistas). Mas tal narrativa está sujeita a revisão, por possuir, a nosso ver, um caráter até certo ponto a-histórico e determinístico, valorizando sobretudo o processo de criação da instituição a partir de ações e iniciativas individuais. Deste modo, faz tabula rasa dos antecedentes, do interesse e das diversas experiências realizadas pelos próprios militares brasileiros no desenvolvimento das técnicas de paraquedismo, que de fato, como veremos, antecederam a experiência de Pessôa 
nos Estados Unidos.

Comecemos então por uma data consideravelmente remota, não com a intenção de estabelecer um "marco", mas para demonstrar que é possível pensar no interesse dos militares brasileiros pela ascensão ao espaço como um processo que acompanhou as tendências e o desenvolvimento das tecnologias bélicas nessa área. Assim, poderíamos assinalar que já, em 1867, durante a Guerra do Paraguai, o governo brasileiro, a pedido de Caxias, havia adquirido dos Estados Unidos dois balões aerostáticos, que foram utilizados como postos de observação na região do Tuiuti. Uso semelhante somente havia sido realizado anteriormente pelos norte-americanos, durante a Guerra de Secessão (Doratioto, 2003).

Os primeiros saltos de paraquedas, devemos lembrar, foram realizados a partir da ascensão de balões, ainda anteriores à própria invenção dos aviões. Mas esse desenvolvimento, em seus primórdios, parece não ter visado as possibilidades de segurança dos aviadores ou, ainda menos, o desembarque de soldados combatentes em operações militares. Os primeiros registros do uso de paraquedas no Brasil são de exibições públicas, como espetáculos que bem seriam qualificados como circenses. Em 1876, data surpreendentemente remota, ocorreram as demonstrações de Theodulo Ceballos, um mexicano que apresentava suas "ascensões aerostáticas" em uma espécie de espetáculo mambembe, percorrendo diversos países das Américas. Ceballos se apresentou no Rio de Janeiro, Curitiba, São Paulo e Recife, incluindo números de paraquedismo em suas exibições ${ }^{2}$. Em 1890, o inglês Stanley Spencer também realizou uma série dessas exibições no Rio de Janeiro, saltando de um balão a seis mil pés de altura e se despenhando "no vácuo, sendo sua descida, a princípio vertiginosa, e depois, abrindo o seu luxuoso paraquedas" ${ }^{3}$.

Também no Rio de Janeiro, ainda no século XIX, foi planejado um protótipo de "base aérea" do Ministério da Guerra, construída em 1894 na Escola de Artilharia e Engenharia em Realengo, na então zona rural do município. Por ocasião da Revolta da Armada, o inventor Augusto Severo, reunido aos engenheiros Gabriel Junqueira e Mário Rôxo, ao químico Domingos de Barros e ao coronel Eduardo de Borja Reis, recebeu incentivos do governo do marechal Floriano Peixoto para construir o Bartolomeu de Gusmão, um dirigível inflado com hidrogênio, de 57 metros de comprimento. A intenção era utilizar o aparelho contra as forças

\footnotetext{
${ }^{2}$ As exibições de Ceballos ficaram registradas em diversos jornais, tanto em propagandas de divulgação quanto nos noticiários. Ver, por exemplo, O Globo, de 7 de março de 1876 ou o Correio Paulistano, de 9 de abril de 1876. Ao balão eram afixados cabos com argolas, nas quais o aeronauta se pendurava para executar acrobacias. Na divulgação, seu número de paraquedismo era por vezes anunciado com a promessa de ser executado por "seu companheiro de viagem" e em outras por "um habitante da cidade". Tratava-se de um engodo: Ceballos levava na ascensão um pequeno cão, que era equipado com um paraquedas e lançado sobre o público.

${ }^{3}$ Sobre as exibições de Stanley Spencer no Brasil, ver registros no Correio Paulistano, de 20 de abril de 1890 ou no Diário de Pernambuco, de 7 de setembro de 1890. É pouco provável que o balão de Spencer tivesse possibilidade de atingir 6.000 pés, medida talvez superestimada a fim de atrair e impressionar o público. Mas mesmo de uma altitude consideravelmente reduzida já seria possível a realização de um salto de paraquedas. A título de comparação, os saltos atualmente realizados pelos militares da Brigada Paraquedistas se dão a partir de 1.000 pés, que equivalem a aproximadamente 304 metros.
} 
navais rebeladas, mas a experiência sofreu diversos revezes: a liga de alumínio necessária para a barca, inexistente nos estoques, foi substituída por bambu, e a fragilidade do material não permitiu bons resultados; uma noite, metade do galpão, construído às pressas, ruiu em virtude do rompimento de suas amarrações. E, embora em algumas evoluções realizadas em fevereiro de 1894 o balão tenha demonstrado equilíbrio para o voo, um acidente partiu a barca e danificou sua estrutura, que não pode ser recuperada a tempo de demonstrar utilidade em combate. As experiências de Severo em Realengo, embora ineficientes em seu objetivo principal, deixaram um parque de aerostação como legado para a Escola de Artilharia e Engenharia, que já contava, em 1908, com quatro balões e outros materiais adquiridos na França e utilizados em experiências de aeronavegação.

Não raramente, tais experiências culminavam em desastre. O próprio Severo foi uma das vítimas, tendo falecido em Paris, em 1902, devido à explosão do seu dirigível Pax. Em Realengo, os ensaios de dirigibilidade também causaram a morte do tenente Juventino Fernandes da Fonseca, em 1908. Juventino fazia parte de um grupo de militares enviado à Europa para aperfeiçoamento de conhecimentos profissionais, e havia participado de treinamentos de navegação aérea na França. De volta ao Brasil, deveria realizar uma demonstração de voo às autoridades, tripulando um balão que, retido por um cabo, atingiria a altitude de 200 metros. A experiência terminou tragicamente: o cabo de retenção se rompeu e o balão foi arrastado pelo vento, chocando-se com a serra do Barata e provocando a morte do piloto (Costa, 2003).

No ano seguinte, o capitão Joaquim de Castro recebeu apoio do Estado-Maior do Exército para a realização de experiências com um dispositivo de sua própria criação, denominado auto-paraquedas. Construído com o ajuda do Arsenal de Guerra, o aparelho poderia retardar a queda de um balão aerostático, e foi testado com sucesso em um dos balões do parque da Escola de Artilharia e Engenharia ${ }^{4}$. Embora os registros não detalhem tal finalidade, não deixa de ser razoável supor a intenção do militar no uso de sua invenção como equipamento de segurança do voo, que permitiria ao piloto ou ao tripulante sobreviverem à queda em caso de pane, evitando acidentes fatais como o do ano anterior.

É justamente pela possibilidade de uso como equipamento de segurança que irá se consolidar o interesse pelo desenvolvimento dos paraquedas, sobretudo com o advento de aeronaves mais modernas e a criação do curso de aviação da Escola Militar, sob influência da Missão Francesa, em 1919. Assim, ao final da década de 1920, os dispositivos e as técnicas de paraquedismo já se encontravam consideravelmente evoluídas, permitindo a execução de proezas aéreas ainda mais arrojadas do que aquelas exibidas algumas décadas antes. Era a vez de personagens como o italiano Genaro Maddaluna e do argelino Achiles Hypolito Garcia (posteriormente naturalizado brasileiro com o nome de Charles Astor) surgirem em cena e se apresentarem em eventos esportivos ou cívicos, recebendo considerável destaque nos periódicos nacionais. Essa vertente da atividade paraquedista não era uma exclusividade nacional. Em outros países também há registros do desenvolvimento do paraquedismo como

\footnotetext{
${ }^{4}$ Correio da Manhã, 3 de dezembro de 1909.
} 
um misto de esporte e entretenimento, chegando-nos notícias de apresentações dessa natureza na Inglaterra, França, Estados Unidos, Alemanha, Rússia e Japão.

\section{A criação da Escola de Paraquedistas}

O grau de desenvolvimento atingido pelos equipamentos passou a possibilitar o uso do paraquedas além das funções de segurança ou esportiva. Os exércitos da Rússia, da Alemanha e da França visualizaram a possibilidade da sua utilização em manobras militares, criando ainda na década de 1930 centros de treinamento de paraquedismo. Alemanha e Rússia, particularmente, já utilizaram tropas de paraquedistas nas manobras iniciais da Segunda Guerra. Destacam-se os alemães, que mesmo sofrendo pesadas baixas iniciais, aperfeiçoaram a formação das Fallschirmjäger e obtiveram resultados estrategicamente importantes com o emprego de tropas aeroterrestres nas campanhas da Noruega e da Dinamarca em abril de 1940, além de maiores sucessos na Bélgica, na Holanda e na França no mesmo ano.

Também é provável que a percepção das vantagens estratégicas obtidas pelas tropas paraquedistas alemãs esteja entre os fatores que levaram o Departamento de Guerra norteamericano a anunciar, em 3 de outubro de 1940 - mais de um ano antes da sua entrada oficial na guerra - que estava em plena formação um corpo de paraquedistas para o seu próprio exército. $O$ Globo, de 4 de outubro de 1940, noticiava que o primeiro batalhão de paraquedistas dos Estados Unidos já estaria composto com um efetivo de 500 homens, anúncio feito (convenientemente, podemos supor) às vésperas da visita de uma comitiva de oficiais latino-americanos a Fort Benning, na Georgia, onde funcionaria o centro de treinamento da nova especialidade. Representando o Brasil, encontrava-se o general Gois Monteiro, então Chefe do Estado-Maior do Exército, que assistiu em solo americano demonstrações de grandes manobras militares ${ }^{5}$.

Paralelamente, continuava sendo amplamente divulgada a organização e o poderio militar dos paraquedistas alemães, principalmente após a batalha pela ilha de Creta, na qual a Alemanha teria lançado em combate três divisões de paraquedistas, das onze que possuiria ${ }^{6}$. No início do ano seguinte, em outra operação de grande repercussão, as forças alemãs utilizaram paraquedistas para desbaratar uma ofensiva iniciada pelos russos contra o corredor alemão em Leningrado?.

Após sua entrada na guerra, no final de 1941, o exército americano quadruplicou a unidade experimental de paraquedistas, formando quatro batalhões de 415 homens cada. Agora, a prática do paraquedismo não podia deixar de despertar interesse crescente entre os militares brasileiros, embora seu emprego em solo nacional ainda estivesse mais relacionado

\footnotetext{
${ }^{5}$ Jornal do Brasil de 18 de outubro de 1940.

${ }^{6}$ Jornal do Brasil, 28 de janeiro de 1941.

${ }^{7}$ Jornal do Brasil, 25 de fevereiro de 1942.
} 
às exibições públicas do que às finalidades bélicas. Em São Paulo, por exemplo, Julio Américo dos Reis, um major que exercia o cargo de diretor do Parque Aeronáutico, fundou uma escola de paraquedismo e se apresentou com vinte paraquedistas no Rio de Janeiro em 19 de outubro de 1941, nas comemorações da "Semana da Asa", promovida pelo recém-criado Ministério da Aeronáutica ${ }^{8}$.

De certo modo, a iniciativa de Julio Américo - omitida na história oficial do paraquedismo militar brasileiro - poderia levantar certas ressalvas sobre o "pioneirismo" dos militares formados em Fort Benning. Esta mesma questão está presente na omissão ao registro publicado no Correio da Manhã, de 13 de janeiro de 1943, sob o título Paraquedistas da $F A B$ - Os dez primeiros cadetes do ar que foram diplomados. A notícia informa que Henrique Fontenelle, tenente-coronel Comandante da Escola de Aeronáutica, havia levado à presença de Salgado Filho, Ministro da Aeronáutica, dez alunos do terceiro ano daquela escola que haviam concluído um estágio de paraquedismo realizado em São Paulo sob a direção do já citado Charles Astor. No curso, realizado entre 23 de dezembro de 1942 e 8 de janeiro de 1943, cada aluno havia realizado três saltos de paraquedas, demarcando o que a notícia denominava "a primeira formação de paraquedistas realizada por iniciativa Força Aérea Brasileira". A relação desses militares registra os seguintes nomes:

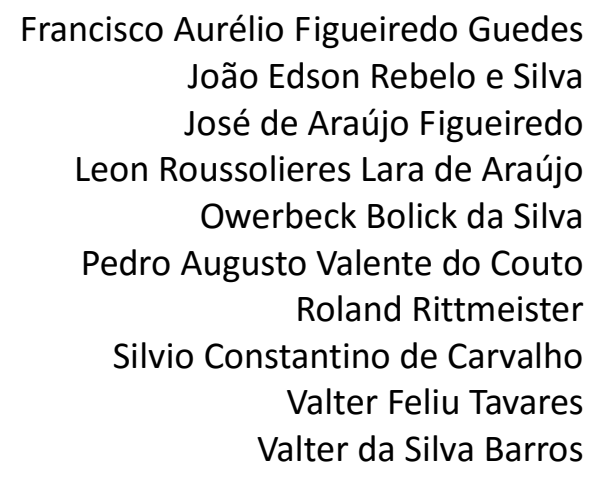

Não podemos nos furtar a uma análise, ainda que breve, do "esquecimento" desses militares na memória do paraquedismo militar brasileiro. Uma justificativa possível seria a de que, embora utilizando técnicas de paraquedismo e realizando o curso inseridos em uma organização militar, os objetivos da habilitação desses paraquedistas, futuros pilotos de aeronave, seria distinto dos paratroopers americanos, cujo centro de formação se destinava ao treinamento de grandes contingentes de tropa para serem lançados em situações de combate. De qualquer modo, o registro desperta questões a respeito da real necessidade de buscar no exterior o domínio de técnicas e equipamentos que, aparentemente, já eram conhecidas em território nacional.

Retornando a atenção para a guerra em curso, encontraremos uma resposta parcial para a questão acima na agenda de negociações e nos debates sobre o alinhamento político e militar entre Brasil e Estados Unidos, que envolvia a concessão de financiamento e

\footnotetext{
${ }^{8}$ Jornal do Brasil, 2 de outubro de 1941.
} 
assessoria norte-americanos para a modernização das Forças Armadas brasileiras. Um dos primeiros resultados dessas discussões foi a criação, em outubro de 1940, da Comissão Mista Brasil-Estados Unidos, com a finalidade de trabalhar no aprimoramento das medidas comuns de defesa. Em janeiro de 1941, um acordo assinado entre os dois países permitiu a instalação no Rio de Janeiro de duas missões militares norte-americanas (no Exército e na Aviação), e a assinatura de um novo acordo, em maio de 1942, criou comissões militares nos dois países, encarregadas de desenhar os planos de defesa conjunta e elevar a capacitação dos militares brasileiros.

Essas ações norte-americanas para aproximação dos dois países estão inseridas em um contexto mais amplo, que Gerson Moura (1984) identificou como uma ostensiva campanha de penetração cultural desencadeada no início dos anos 1940, como parte da estratégia dos Estados Unidos frente ao desafio de enfrentar o Eixo e se consolidar como grande potência. Com essa finalidade, foi criado em agosto de 1940 o Office of the Coordinator of Inter-American Affairs (OCIAA), diretamente vinculado ao Conselho de Defesa Nacional dos Estados Unidos. O amplo espectro de ações dessa agência explicaria o convite, realizado em junho de 1943, aos jornalistas brasileiros Arlindo Pasqualini, da Folha da Tarde de Porto Alegre, Wilson Lins, do Imparcial da Bahia e Hugo Barreto, do O Globo, para assistir demonstrações dos avanços do paraquedismo militar em Fort Bening ${ }^{9}$. Essas demonstrações, embora realizadas em uma base militar, foram abertas não apenas para comitivas militares mas, aparentemente, para todos aqueles que pudessem formar opiniões e influenciar positivamente os objetivos de aproximação norte-americanos. Em agosto, foi a vez do Ministro da Guerra, Eurico Dutra, visitar a mesma base militar. Dutra, a quem coube comandar o processo efetivo de aproximação entre Brasil e Estados Unidos no que dizia respeito às questões militares, realizou essa visita acompanhado dos generais Leitão de Carvalho, membro da Comissão Conjunta de Defesa, Zenóbio da Costa e Alcio Souto, e foi recebido exatamente pelos comandantes da Escola de Infantaria e da Escola de Paraquedistas $^{10}$.

No que diz respeito à gênese do corpo de paraquedistas nacionais, o clímax dessas aproximações foi a indicação, em 1944, do capitão Roberto de Pessôa para realizar o curso de paraquedismo da Airborne School. Com um currículo de chefe do Departamento de Educação Física da Escola de Aviação Militar, Diretor da Escola Nacional de Educação Física e Desportos, atleta, piloto civil e entusiasta da aviação, Pessôa já havia integrado, em 1936, a delegação brasileira que participou dos Jogos Olímpicos de Berlim, na condição de Subchefe da Delegação de Estudantes de Educação Física no Congresso Internacional de Educação Física, desenrolado paralelamente aos jogos. Na oportunidade, realizou articulações que lhe permitiram frequentar o curso de piloto de planadores do exército alemão, em uma base militar instalada em Wenningstedt, na Ilha de Sylt. Cabe registrar que o centro de formação de paraquedistas alemães funcionava em instalações vizinhas da escola de planadores, e que Pessôa tentou, sem sucesso, obter autorização para frequentá-lo. Mas tanto em Sylt, quanto

\footnotetext{
${ }^{9}$ O Globo, 12 de junho de 1943.

${ }^{10}$ A Noite, 27 de agosto de 1943.
} 
na Georgia, o brasileiro tratou e se informou sobre questões ligadas à criação das tropas aeroterrestres em exércitos europeus e no norte-americano, coletando materiais e plantas relativos às áreas especiais de treinamento. Foram modelos e ideias colhidos nestas ocasiões que subsidiaram a construção da versão nacional do centro de treinamento e a estruturação da Escola de Paraquedistas ${ }^{11}$.

Em 4 de abril de 1945, o Correio da Manhã noticiava que Pessôa havia completado os "treinamentos básico e adiantado em técnicas paraquedistas", que de fato havia concluído em 22 de outubro de 1944, em Fort Benning. Ainda nos Estados Unidos, o oficial se qualificou como piloto de planadores no Centro de Transporte Aéreo do Exército em Camp Mackall, na Carolina do Norte, completando seis meses em treinamento nas escolas militares americanas antes de regressar ao Rio de Janeiro. Em agosto de 1945, O Globo anunciava, sob a epígrafe $O$ Brasil terá também seus corpos de paraquedistas:

Será fundado no Rio, um centro semelhante aos mais famosos do mundo as primeiras providências do Ministério da Guerra - aberto o voluntariado a aeronáutica vai dar parecer. $O$ paraquedismo no Exército, ao que estamos seguramente informados, vai tornar-se realidade, devendo, dentro em breve, ser criada a respectiva escola nos moldes do Forte Benning, dos Estados Unidos, e de outros estabelecimentos mundialmente conhecidos. Para isso, o Ministério da Guerra já está realizando o trabalho preparatório de abertura do voluntariado dos corpos de tropa afim de que, uma vez estabelecida em lei, a fundação do estabelecimento referido, esteja já composto o seu corpo de alunos. Já se cogita também da seleção dos futuros instrutores que irão adquirir os conhecimentos necessários naquele instituto militar de ensino norte-americano. Ao mesmo tempo, o respectivo titular já submeteu o ante-projeto de criação da Escola à consideração do Ministério da Aeronáutica, que deverá apresentar sugestões e o seu parecer. O precursor da ideia, entre nós, é o capitão Roberto Pessôa, ex-diretor da Escola Nacional de Educação Física que vem de fazer o curso de paraquedismo no referido Forte.

Com efeito, no mesmo ano foi ativado o Núcleo de Formação e Treinamento de Paraquedistas, que sob a supervisão de Pessôa selecionou uma nova turma de voluntários para frequentar o Basic Airborne Course. O primeiro grupo de militares enviado aos Estados Unidos foi constituído pelos seguintes oficiais e sargentos, que concluíram o treinamento de paraquedismo em 20 de dezembro de 1945:

Adhemar Machado Ribeiro, primeiro-tenente

Alberto Andres, segundo-sargento Alírio Granja, segundo-tenente Armando Renan D`Avila Duarte, primeiro-tenente

\footnotetext{
11 O acesso ao relatório produzido por Roberto de Pessôa no retorno de Fort Benning, bem como a uma quantidade considerável de informações, documentos e imagens relativas à sua vida e carreira militar foi possibilitado através do acervo do Museu Aeroterrestre.
} 
Celso Nathan Guaraná de Barros, segundo-tenente Darcy Tavares de Carvalho Lima, capitão Décio Teixeira Borges, segundo-sargento Demócrito Soares de Oliveira, capitão Edegar Marques, segundo-sargento Edy Miró Mendes de Moraes, capitão Fernando Retumba Carneiro Monteiro, primeiro-tenente Gastão Mayer de Oliveira, segundo-sargento Gladstone Maia, primeiro-tenente Hortilho de Oliveira Chueire, primeiro-sargento José Roberto Monteiro Wanderley, segundo-tenente José de Escobar Beviláqua, segundo-tenente Octávio Magdalena Lobianco, segundo-tenente Paulo Aury Bollick Angelo, segundo-tenente Waldo Russo, primeiro-tenente

Realizo um pequeno desvio na narrativa. Em 1995, por ocasião da passagem dos cinquenta anos da viagem a Fort Benning, observamos um intenso movimento interno de valorização e resgate da memória e da história da instituição, materializado, entre outras iniciativas, através da realização de uma série de homenagens dirigidas para os veteranos da Airborne School. Como parte dessas homenagens, um marco de pedra foi inaugurado em frente ao quartel-general da brigada, sendo-lhe afixadas placas de bronze gravadas com os nomes daqueles primeiros voluntários, que passaram a receber o tratamento de "pioneiros", além de permanentes deferências e destaques especiais por ocasião das comemorações e solenidades militares. Também se inclui nesse movimento a inauguração, em dezembro de 2005, do "Museu Aeroterrestre", que exibe objetos pessoais, fotos e imagens das atividades desenvolvidas pelos "pioneiros" e por outros personagens ligados ao desenvolvimento nacional do paraquedismo militar.

Um aspecto interessante dessas tentativas de valorização do passado, peculiar à instituição, foi o estabelecimento de um "almanaque", do qual consta uma numeração que ordena cada um dos militares que concluíram o curso básico paraquedista, desde 1944 até os dias atuais. Roberto de Pessôa recebeu o número "01", e sucessivamente foi sendo aplicada tal ordenação em uma ordem cronológica de conclusão do curso de paraquedismo, independente da precedência hierárquica. No âmbito da brigada, essa ordem concede certo status, com uma importância simbólica crescente no sentido inverso ao valor numérico, ou seja: quanto menor o número de paraquedista, maior o valor reconhecido pelos demais, encontrando-se no ápice os "pioneiros", que possuem os números de "01" até "48".

Mas a respeito desse culto aos "pioneiros" há um fato curioso. O oficial do Exército Octávio Alves Velho servia como professor de Língua Portuguesa na Academia Militar de West Point entre 1948 e 1951, e durante sua estada no exército norte-americano deslocou-se até Fort Benning para realizar o curso de paraquedismo. No retorno ao Brasil foi classificado na Escola de Paraquedistas e lá submetido à chamada "revalidação" uma espécie de "repetição" do curso em território nacional - uma exigência para os militares que haviam 
obtido o brevet no estrangeiro. Mas a revalidação dos demais "pioneiros" (que realizaram o curso norte-americano entre 1945 e 1948) havia sido realizada em 1949, e os cursos nacionais já aconteciam regularmente desde então. Assim, na numeração oficial Octávio recebeu o número de ordem 768 , sendo situado, juntamente com alguns poucos oficiais, no quarto curso realizado por soldados no ano de 1952. Tornou-se, dessa forma, um "pioneiro esquecido" ao qual não foram prestadas as homenagens concedidas aos voluntários selecionados por Roberto de Pessôa.

Retomemos o curso da narrativa. O retorno dos militares enviados a Fort Benning em 1945 foi imediatamente sucedido pela expedição do Decreto-Lei 8.444, de 26 de dezembro de 1945, que criou no Ministério da Guerra a Escola de Paraquedistas, destinada à formação da tropa dessa especialidade. Assinado por José Linhares, presidente do Supremo Tribunal Federal investido na chefia do governo em vista da destituição de Vargas e da inexistência do vice-presidente da República e dos presidentes das duas casas do Congresso, fechadas desde 1937, o decreto previa uma escola integrada por órgãos de administração, duas Companhias de Tropa, um Corpo de Alunos constituído por duas Companhias de Infantaria, uma Bateria de Artilharia, uma Seção de Engenharia e uma Companhia de Especialistas, com Pelotões de Transmissões, Distribuições e Conservadores-Artífices. Os Ministérios da Aeronáutica e da Guerra também foram autorizados a planejar e propor a criação de uma Escola de Pilotos de Planadores, que nunca chegou a se concretizar.

A Escola de Paraquedistas foi instalada na Vila Militar do então Distrito Federal. Suas primeiras estruturas, incluindo a "área de estágios" (área dotada de equipamentos próprios para o treinamento de paraquedismo), foram construídas no local onde ainda hoje se encontram, as terras da antiga fazenda Sapopemba na Zona Oeste da cidade do Rio de Janeiro, em uma localização convenientemente próxima da Base Aérea dos Afonsos, que supriria sua necessidade de apoio aéreo. A consideração que a localização da base aérea havia sido determinada, décadas antes, pela proximidade da localidade com a Escola Militar do Realengo, onde se originaram os cursos de aviação militar, tece certa continuidade entre o estabelecimento da Escola de Paraquedistas e outras condições estruturais e objetivos já presentes no Exército, em detrimento da hipótese institucional de uma "criação" exclusiva a partir de iniciativas individuais e de um modelo puramente estrangeiro da década de 1940.

Ao extenso e detalhado relatório que elaborou no retorno dos Estados Unidos, Pessôa anexou um "Ante-Projeto do Decreto-Lei de Criação da Escola de Paraquedistas", cujo texto, praticamente sem alterações, foi aquele assinado em 26 de dezembro de 1945 e publicado no Diário Oficial da União dois dias depois. Entretanto, para seu dissabor, a única alteração acrescida à sua proposta seria justamente a que viria a contrariar seu intento de se tornar o primeiro comandante da tropa de paraquedistas brasileiros. Na redação de Pessôa, o Artigo primeiro do decreto previa: "fica criada, no Ministério da Guerra, a Escola de Paraquedistas, destinada à formação da tropa dessa especialidade". Mas um Parágrafo único foi introduzido, acrescentando: "O Comando da Escola de Paraquedistas caberá a um oficial superior com o curso de Estado-Maior, de preferência especializado". Na prática, a expressão que grifamos trazia embutida a determinação de que o curso de paraquedismo não seria 
condição obrigatória para a função de comandante da unidade, mas sim o curso de EstadoMaior, que Pessôa não possuía. A parte, observemos que nenhum dos selecionados por Pessôa para a viagem a Fort Benning era hierarquicamente superior a ele, o que the garantiria o comando da tropa caso sua proposta não houvesse sofrido alterações.

Excluída a possibilidade de Pessôa assumir o comando inicial da unidade, a tarefa coube ao coronel Nestor Penha Brasil, oficial que recentemente havia retornado da campanha da Força Expedicionária Brasileira na Itália. O inconformismo de Pessôa com a preterição foi causa de rusgas pessoais entre os dois oficiais, e após poucos meses foi afastado da Escola de Paraquedistas, para onde retornaria apenas em 1957, após a partida de Penha Brasil.

Seria possível afirmar que a frustração pelo preterimento o acompanhou por um longo tempo? Em 1992, quase meio século após o episódio, Pessôa foi convidado a transmitir uma mensagem aos leitores de uma publicação militar portuguesa e referiu-se às dificuldades enfrentadas para a implantação do paraquedismo militar no Brasil, atribuindo-as às "limitações, agravadas pela falta de mentalidade reinante e ausência de um Estado-Maior devidamente qualificado", além do "amolecimento do pós-guerra, período desprimoroso" que precisou ser enfrentado pela "vontade férrea dos pioneiros já qualificados". O discurso, interpretado à luz dos fatos, de certo modo parece voltado a atingir Penha Brasil e sua experiência como combatente, o qual representaria o "Estado-Maior desqualificado e amolecido" do pós-guerra, e valorizar, simultaneamente, a experiência no exterior do próprio Pessôa e dos voluntários por ele selecionados ${ }^{12}$.

$\mathrm{Na}$ verdade, as experiências e qualificações de Penha Brasil como militar combatente não se resumiam à campanha na Itália. Nascido no Rio de Janeiro, em 1900, formou-se no curso de Artilharia da Escola Militar do Realengo em 1919 e serviu os anos iniciais da carreira em Itaqui (RS), Itu (SP) e na Vila Militar, no Rio de Janeiro. Designado para participar das operações de repressão à Coluna Prestes, passou parte de 1926 no Nordeste do país. Tendo se posicionado contra a Revolução de 1930, desertou do Exército em 1932 para apoiar a Revolução Constitucionalista de São Paulo, mas com a derrota paulista foi punido pelas autoridades militares, sendo reformado administrativamente em agosto de 1933. Retornou ao serviço ativo em 1934, sendo designado para servir em Juiz de Fora (MG) e, em seguida, em Porto Alegre (RS).

Em 1935, tornou-se oficial-de-gabinete do Ministro da Guerra, deixando o cargo em 1936, quando seguiu para Paris, onde cursou a Escola Superior de Guerra daquele país durante dois anos. Com a constituição da 1a Divisão de Infantaria Expedicionária e a definição da participação brasileira na Segunda Guerra Mundial, Penha Brasil integrou o terceiro grupo de Artilharia Divisionária, sendo enviado para realizar cursos em bases militares norte-americanas. Em 22 de setembro de 1944 embarcou para a Itália, retornando ao Brasil em junho de 1945. Nesse mesmo mês, foi promovido a coronel e entre setembro e

\footnotetext{
12 Trata-se de uma mensagem redigida por Pessôa a pedido dos editores da "Revista Boina Verde", publicação da tropa paraquedista de Portugal, em 23 de setembro de 1992.
} 
novembro seguintes esteve novamente na Europa, a convite do governo norte-americano.

Penha Brasil assumiu o comando do Núcleo de Formação e Treinamento de Paraquedistas do Exército em março de 1946. Em janeiro de 1949 recebeu a instrução básica de paraquedismo e em agosto de 1952 foi promovido a general-de-brigada, continuando à frente da tropa até fevereiro de 1955, quando iniciou o curso da Escola Superior de Guerra. Seus quase nove anos à frente da Escola de Paraquedistas e do Núcleo da Divisão Aeroterrestre tornaram seu comando o mais longevo da história da tropa, superando em muito a média de dois anos de duração que caracteriza esse tipo de comissão. Falecido no Rio de Janeiro no dia 21 de maio de 1964, foi promovido post mortem ao posto de marechal. Como homenagem póstuma seu nome foi agregado à organização militar originada na Escola de Paraquedistas, que recebeu a denominação de "Centro de Instrução Paraquedista General Penha Brasil".

Como vimos, após 1945 seis novas turmas foram enviadas sucessivamente para a Georgia, sendo a última (a desconsiderar o feito de Octávio Velho) em 1948. A finalidade dessas viagens era dispor de uma quantidade de especialistas que pudessem implantar de fato uma organização militar aeroterrestre no Brasil, atuando como instrutores dos cursos realizados em solo nacional. Finalmente, em 1949, foi iniciado o funcionamento da Escola de Paraquedistas, que chegou ao final daquele ano com o registro da formação de 133 alunos. Em 1953, foram ampliados os cursos e atividades da escola, dando origem ao Núcleo da Divisão Aeroterrestre, que existiu até 1969. Nesse ano foi criada a Brigada Aeroterrestre, cuja denominação foi alterada, em 1971, para Brigada Paraquedista e, finalmente, para Brigada de Infantaria Paraquedista, no ano de 1985.

Ao longo da segunda metade do século $X X$, o quadro de pessoal da brigada se ampliou, acompanhando suas sucessivas reestruturações. Entre 1944 e 1948, apenas 47 militares brasileiros frequentaram o curso de paraquedismo em Fort Benning. Mas números que englobam o Exército Brasileiro, a Marinha do Brasil, a Força Aérea Brasileira e Forças Armadas estrangeiras apontam que a Escola de Paraquedistas formou 720 paraquedistas, no período de 1949 até 1951; o Núcleo da Divisão Aeroterrestre formou 18.516 militares, entre 1952 e 1969; a Brigada Aeroterrestre, em três anos de existência, teve 4.486 alunos; a Brigada Paraquedista teve 18.879 alunos entre 1973 e 1985; e a Brigada de Infantaria Paraquedista formou 43.824 militares de 1986 até julho de 2015. Assim, considerando seus 70 anos de existência, computa-se a passagem de mais de 86.000 paraquedistas militares em suas fileiras.

\section{Conclusão}

A falta de maiores informações e estudos sobre a história da Brigada de Infantaria Paraquedista é para nós um dado inquietante, considerando a expressão dessa organização militar no cenário político nacional, bem como no processo de modernização das Forças 
Armadas a partir da segunda metade do século XX. No futuro da pesquisa em curso, acreditamos que a compreensão da dimensão desses e de outros aspectos da questão será ampliada, quando a analisarmos dentro de um quadro mais amplo, tornando o estudo, paralelamente, uma investigação sociocultural sobre os militares, abrangendo múltiplos recortes e pontos de vista sobre o serviço e a profissão militar.

Concedemos certo destaque aos personagens que estruturaram os primeiros anos de funcionamento da atual Brigada de Infantaria Paraquedista. Esse recorte não pretendeu exaltar suas atuações, mas enquadrá-las teoricamente em um princípio de análise da cultura organizacional que determina a concessão de especial atenção à figura dos fundadores de uma determinada instituição. Com efeito, tais personagens desempenharam um papel fundamental, pois ao mesmo tempo que conceberam os projetos originais, tiveram o poder de estruturar, desenvolver e tecer os elementos simbólicos correspondentes a esses projetos. Essa visão subsidia a interpretação, por exemplo, do antigo conjunto de símbolos - a boina vermelha, os calçados marrons e o distintivo metálico prateado (um paraquedas aberto ladeado por duas asas), que expressam a ligação dos soldados paraquedistas com a instituição e, consequentemente, com os valores que esta considera ética e socialmente desejáveis: particularidade e destaque, conferidos pela visibilidade dos uniformes e outros símbolos diferenciados.

Penetrar no passado da Brigada de Infantaria Paraquedista, equivale a desvendar uma história e uma cultura transmitidas e reproduzidas por mecanismos próprios às instituições militares. No museu situado na própria brigada, é possível observar objetos que celebram e cultuam os primeiros paraquedistas como "pioneiros", um mito fundador da instituição. $O$ fato desses elementos terem sido reunidos recentemente mostra que existe uma vontade real de valorizar uma tradição própria e peculiar, que procura justificar e legitimar a escolha preferencial pela memória dos pioneiros, com destaque para Nestor Penha Brasil e Roberto de Pessôa. Quanto ao último, sua viagem a Fort Benning é interpretada no seio da organização que ajudou a fundar como um ato isolado de iniciativa e coragem moral, representando um marco supostamente desvinculado das condicionantes políticas e doutrinárias que de fato estavam em curso no País e dentro do Exército de sua época. A evocação permanente dessa interpretação busca criar uma percepção específica do passado, encaminhando-o para a memória de uma iniciativa individual e arrojada, inteligível não pela sua correção histórica, mas como um exemplo convenientemente selecionado como modelo para indivíduos que tem como ofício o risco de saltar de paraquedas a partir de uma aeronave em voo.

Artigo recebido em 08/07/2016

Artigo aprovado para publicação em 10/10/2016 


\section{Referências}

\section{Jornais e revistas}

A Noite. Rio de Janeiro, 1911 - 1957. Periodicidade diária.

Correio da Manhã. Rio de Janeiro, 1901 - 1974. Periodicidade diária.

Jornal do Brasil. Rio de Janeiro, 1891 - 2010. Periodicidade diária.

O Globo. Rio de Janeiro, 1925 - atual. Periodicidade diária.

Tecnologia e Defesa. Suplemento especial n. 28, 2015.

\section{Livros e artigos}

BRUNO, Daniela Caldeira. "Brasil acima de tudo!" Narrativa e construção de identidades: o combatente pára-quedista do Exército Brasileiro. 2010. 281 f. Tese (Doutorado em Letras). Pontifícia Universidade Católica, Rio de Janeiro, 2010.

CARVALHO, José Murilo. Forças Armadas e Política no Brasil. In: CARVALHO, J. M. Forças armadas e política, 1930 - 1945. A Revolução de 30. Rio de Janeiro: Zahar, 2005.

COSTA, Alessandra de Sá Mello da; BARROS, Denise Franca; MARTINS, Paulo Emílio Matos. Perspectiva histórica em administração: novos objetos, novos problemas, novas abordagens. Revista de Administração de Empresas. São Paulo, v. 50, n. 3, p. 288-299, 2010.

COSTA, Fernando Hippólyto da. Síntese cronológica da aeronáutica brasileira (1685-1941). Colecão Aeronáutica. vol. 8. INCAER, 2003.

Centro de Pesquisa e Documentação de História Contemporânea do Brasil. Dicionário Histórico Biográfico Brasileiro pós 1930. 2a ed. Rio de Janeiro: FGV, 2001.

DORATIOTO, Francisco. Maldita Guerra: nova história da Guerra do Paraguai. 5 ed. São Paulo: Companhia das Letras, 2012. 615p.

FERNANDES, Nelson da Nóbrega. Os militares e o espaço urbano do Rio de Janeiro: um programa de pesquisa em geografia urbana e geografia política. Scripta Nova. Barcelona, v. X, p. 218-227, 2006.

FLEURY, Maria Tereza Leme; FISCHER, Rosa Maria. Cultura e Poder nas Organizações. São Paulo: Atlas, 1996.

MOURA, Gerson. Tio Sam chega ao Brasil: a penetração cultural americana. São Paulo: Brasiliense, 1984.

RODRIGUES, Fernando da Silva. Renovação e Revoltas: a Escola Militar do Realengo de 1918 a 1922. In: I Encontro Nacional da Associação Brasileira de Estudos de Defesa - ABED, 2007, São Carlos. Anais da Associação Brasileira de Estudos de Defesa. São Carlos: UFSCar, 2007. v. 
1. p. $1-69$

. Da chegada da missão militar no Brasil em 1936 à dominação total da influência doutrinária do exército do Tio Sam no exército do Zé Carioca. Cadernos da FaEL, v.1, p. 1-15, 2008.

SANTOS, Bruna Mello dos. Achiles Hypolito Garcia, Charles Astor, pioneiro do paraquedismo e da ginástica acrobática no Brasil. Rio de Janeiro: Instituto Histórico-Cultural da Aeronáutica, 2015.

SCHEIN, Edgard. Organizational culture and leadership (3a ed.). San Francisco: Jossey-Bass, 2004.

VIANA, Claudius Gomes de Aragão. História, memória e patrimônio da Escola Militar do Realengo. 2010. 176 f. Dissertação (Mestrado em Bens Culturais e Projetos Sociais). Fundação Getúlio Vargas, Rio de Janeiro, 2010. 